\title{
Belgian heart disease prevention project: comparison of self-reported smoking behaviour with serum thiocyanate concentrations
}

\author{
MARCEL KORNITZER, ${ }^{1}$ ANNE VANHEMELDONCK, ${ }^{1}$ PIERRE BOURDOUX, ${ }^{2}$ \\ AND GUY DE BACKER ${ }^{3}$ \\ From the Laboratory of Epidemiology and Social Medicine, ${ }^{1}$ Free University of Brussels, the Laboratory of \\ Radio Isotopes, ${ }^{2}$ St Pieters Hospital, Brussels, and the Laboratory of Hygiene and Social Medicine, ${ }^{3}$ State \\ University, Ghent, Belgium
}

SUMMARY At the end of a multifactorial cardiovascular preventive trial serum thiocyanate was measured in random samples of 1035 cases and 1087 controls. A cut-off point $0.45 \mathrm{mg} / \mathrm{dl}$ $(77 \cdot 6 / \mu \mathrm{mol} / \mathrm{l})$ gave a sensitivity of $82 \cdot 1 \%$ among the cigarette smokers in the control group and a specificity of $91.0 \%$ among the non-smokers. When the intervention and control groups are compared in terms of self-reported smoking behaviour non-significant differences in mean thiocyanate concentration are observed for those who never smoked, ex-cigarette smokers, actual cigarette smokers, and in four different cigarette smoking categories. Our results fail to confirm the reported pessimistic views concerning the validity of self-reported smoking behaviour in subjects taking part in intervention trials.

It has been argued that self-reported smoking behaviour should be interpreted with caution, particularly when subjects are taking part in a controlled trial. ${ }^{1}$ An objective evaluation of self-reported smoking behaviour would be important when differences between experimental and control groups are small and expressed in numbers of cigarettes smoked daily.

In the Belgian Heart Disease Prevention Project significant differences in the percentage of smokers as well as in the amount smoked was observed in a group of high-risk subjects after two years of follow-up. ${ }^{2}$ No significant difference in the percentage of smokers was observed between total intervention and control groups, but the self-reported number of cigarettes smoked daily was significantly lower in the intervention group compared with the control group: consequently we suspected that differences at end-screening, if any, would be detectable only in the mean number of cigarettes smoked daily. We decided, therefore, to use serum thiocyanate as an objective measure of reported smoking behaviour in random samples of both the intervention and control groups.

\section{Material and methods}

Details of the study population and screening techniques have been described elsewhere. ${ }^{3}$ Thirty: factories were paired according to type of industry, and one member of each pair was randomly allocated to the intervention group with the other serving as a control. There were 19409 men aged 40-59 listed, of whom $16222(83.7 \%)$ took part in the base-line examination. In the intervention group-of 7398-all subjects were initially screened for risk factors (systolic blood pressure, resting ECG, weight and height, serum cholesterol concentration, and smoking habits). In the control group of $8824,10 \%$ of all subjects in each factory were randomly selected to undergo the same initial examination as all the subjects in the intervention group; in the other $90 \%$ only an ECG at rest was recorded. For all the subjects in the intervention group and for $10 \%$ of the total control group who underwent the same thorough initial examination, risk scores were established based on the initial results. The 600 subjects belonging to the top $21 \%$ of the risk score distribution were arbitrarily designated as the high-risk group, while the others were called the lower-risk group.

In the intervention group the high-risk subjects received twice a year face-to-face counselling whereas the lower-risk group received written information on their particular risk factors and benefited from the mass campaign. Subjects who smoked five or more cigarettes a day were 
encouraged to quit. At the six-year end screening, random samples of the intervention and control group had serum thiocyanate measured: (1035 of the intervention group and 1087 of the control group). Serum thiocyanate was measured according to the technique of Aldrige ${ }^{4}$ modified by Michajlovsky and Linger ${ }^{5}: 0.5 \mathrm{ml}$ serum were mixed with $2 \mathrm{ml} 15 \%$ trichloroacetic acid and centrifuged for 10 minutes. An aliquot of the supernate $(1.5 \mathrm{ml})$ was transferred to a glass-fitted tube; standards were prepared by mixing $0.3 \mathrm{ml} \mathrm{KSCN}$ solutions $(0 \cdot 1,0 \cdot 25,0.5,0 \cdot 75$, 1.0 , and $1.25 \mathrm{mg} \mathrm{SCN} / \mathrm{dl}$ ) with $1.2 \mathrm{ml} 15 \%$ trichloroacetic acid. The following reagents were then added suquentially to each tube: $0.2 \mathrm{ml}$ saturated bromine water, $0.2 \mathrm{ml} 4 \% \mathrm{As}_{2} \mathrm{O}_{3}$ in $2 \%$ $\mathrm{NaOH}, 1.6 \mathrm{ml} 1 \%$ benzidine $2 \mathrm{HC} 1$ in water, and 2 $\mathrm{ml}$ pyridine. After 30 minutes optical density was read against blank at $525 \mathrm{~mm}$. A serum sample measured in 27 different assays gave a mean \pm SD of $0.61 \pm 0.02 \mathrm{mg} / \mathrm{dl}$ (Interassay CV $=3.5 \%$ ).

\section{Results}

The incidence of ex-smokers during the six years of the trial was almost identical in both the intervention (26.5\%) and control (26.5\%) groups; the incidence was slightly but not significantly higher among the high-risk subjects of the intervention group $(30.9 \%)$ compared with the high-risk control group (28.0\%).

The change between base-line and end-screening in the mean number of cigarettes smoked daily among subjects who smoked cigarettes at base-line ( $=\triangle$ cigarettes/day) was calculated. No differences were observed in $\triangle$ cigarettes/day between total intervention and $10 \%$ random sample of the control group. Nevertheless a significant difference in $\triangle$ cigarettes/day was observed between the high-risk subjects of the intervention group compared with the high-risk control subjects (table 1). When the serum thiocyanate concentrations of the control group are taken as a reference we observed the following results: the lowest mean thiocyanate concentration was found in those who reported having never smoked, a slightly higher mean was observed in excigarette smokers, whereas a significantly higher level was found in those who switched from cigarettes to cigar or pipe, or both; the thiocyanate concentration in the latter group was almost the same as that observed in genuine cigar or pipe smokers, or both (fig 1).

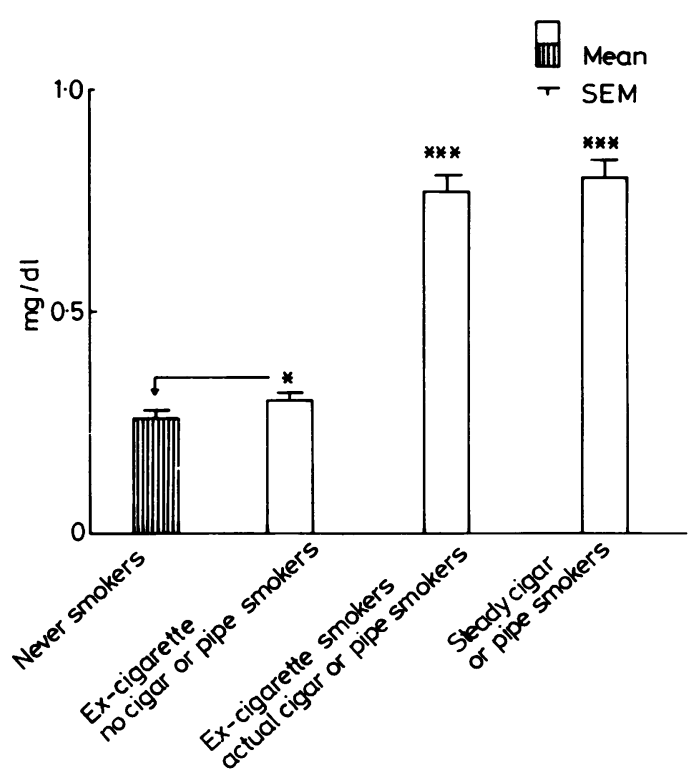

Fig 1 Serum thiocyanate concentrations in 1035 control subjects of the Belgian Heart Disease Prevention Project, according to self-reported smoking behaviour, at final screening.

In fig 2 the mean thiocyanate concentrations (and SEM) are given for non-smokers and for current cigarette smokers by number of cigarettes; a significant gradient is found with increasing numbers of cigarettes smoked; even smokers of one to five cigarettes a day show a significant higher mean thiocyanate concentration compared with nonsmokers. The correlation coefficient between thiocyanate concentrations and number of cigarettes smoked a day is 0.41 .

When thiocyanate concentrations in ex-smokers are compared with those in current cigarette smokers the same difference and gradient are observed.

We evaluated the sensitivity and specificity of the technique in subjects of the control group, as it is

Table 1 Change in number of cigarettes smoked a day by smokers seen at the initial screening and after six years

\begin{tabular}{lllllll}
\hline & \multicolumn{2}{l}{ Intervention group } & & \multicolumn{2}{l}{ Control group (10\%) } & \\
\cline { 2 - 3 } & No of smokers & Mean difference & & No of smokers & Mean difference & $p$ \\
\hline Total & 2182 & -1.5 & -3.7 & 82 & -1.0 & NS** \\
High-risk group & 539 & -1.4 & 0.05 \\
\hline
\end{tabular}

NS $=$ Not significant. 

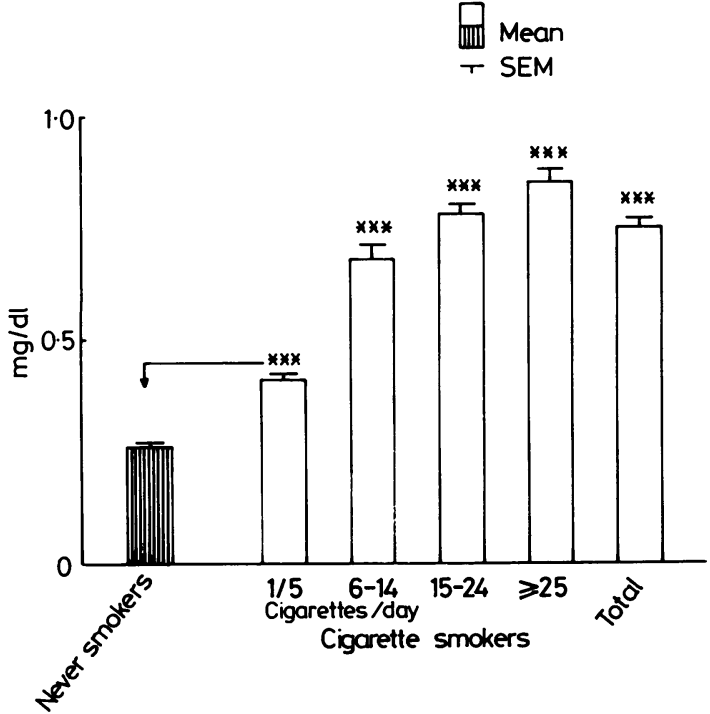

Fig 2 Serum thiocyanate concentrations in 1035 control subjects of the Belgian Heart Disease Prevention Project, according to self-reported smoking behaviour, at final screening.

assumed that they reported their smoking behaviour accurately (table 2). A cut-off point of $0.45 \mathrm{mg} / \mathrm{dl}$ $(77 \cdot 6 / \mu \mathrm{mol} / \mathrm{l})$ gives a sensitivity of $82.1 \%$ among self-reported cigarette smokers, this figure being almost the same for light $(<15 \mathrm{cig} / \mathrm{day})$ and heavy $(\geqslant 15 \mathrm{cig} /$ day) smokers; whereas specificity in nonsmokers and ex-smokers is respectively $91 \%$ and $88.3 \%$.

Cigarette smokers who switched to cigar or pipe, or both, and genuine cigar or pipe smokers or both, are very similar to current cigarette smokers in terms of thiocyanate concentrations: approximately $84 \%$ of them have levels at or above $0.45 \mathrm{mg} / \mathrm{dl}$.

When the intervention and control groups are compared in terms of self-reported smoking behaviour non-significant differences in mean thiocyanate concentrations are observed for those who never smoked, ex cigarette smokers, excigarette smokers who switched to cigar or pipe, or both, and steady cigar or pipe smokers, or both (fig 3).

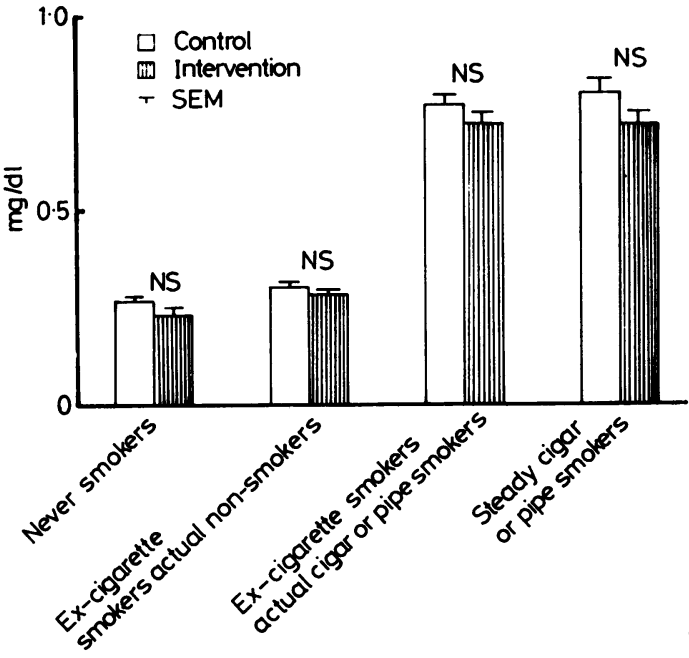

Fig 3 Serum thiocyanate concentrations in control and intervention subjects of the Belgian Heart Disease Prevention Project according to self-reported smoking behaviour at final screening. $N S=$ Not significant.

Furthermore, in none of the four different cigarette smokers' categories, nor in the total group of cigarette smokers were significant differences in thiocyanate concentrations found between the intervention and control groups.

Finally in table 3 the thiocyanate concentrations are presented for random subgroups of 3036 subjects in the intervention group and 393 in the control group who reported cigarette smoking at base-line and who attended the end-screening: no significant differences in thiocyanate concentrations are

Table 2 Specificity and sensitivity of thiocyanate measure in the control group

\begin{tabular}{|c|c|c|c|c|c|}
\hline & \multicolumn{4}{|c|}{ No of subjects with thiocyanate } & \multirow[b]{3}{*}{ Total } \\
\hline & \multicolumn{2}{|c|}{$\geqslant 0.45 \mathrm{mg} / \mathrm{dl}$} & \multicolumn{2}{|c|}{$<0.45 \mathrm{mg} / \mathrm{dl}$} & \\
\hline & No & $\%$ & No & $\%$ & \\
\hline $\begin{array}{l}\text { Never smoked } \\
\text { Ex-cigarette smokers: }\end{array}$ & 18 & 9 & 181 & 91 & 199 \\
\hline $\begin{array}{l}\text { Ex-cigarette smokers: } \\
\text { Non-smokers }\end{array}$ & \multicolumn{4}{|c|}{$\begin{array}{l}\text { Never smoked } \\
\text { Ex-cigarette smokers: }\end{array}$} & 179 \\
\hline Cigar/pipe smokers & 89 & $84 \cdot 8$ & $\begin{array}{r}158 \\
16\end{array}$ & $\begin{array}{l}88 \cdot 3 \\
15 \cdot 2\end{array}$ & $\begin{array}{l}179 \\
105\end{array}$ \\
\hline Steady cigar/pipe smokers & 86 & $84 \cdot 3$ & 16 & $\begin{array}{l}15 \cdot 2 \\
15 \cdot 7\end{array}$ & 105 \\
\hline Cigarette smokers: & 412 & $82 \cdot 1$ & 16 & $17 \cdot 9$ & 102 \\
\hline$<15 /$ day $^{*}$ & 112 & $82 \cdot 3$ & 90 & $\begin{array}{l}17.9 \\
17 \cdot 7\end{array}$ & 502 \\
\hline$\geqslant 15 /$ day* & 299 & 83.3 & 24 & $16 \cdot 7$ & $\begin{array}{l}136 \\
359\end{array}$ \\
\hline & & & 60 & & 359 \\
\hline
\end{tabular}

*Seven missing values. 
Table 3 Mean thiocyanate $(\mathrm{mg} / \mathrm{dl})$ of initial cigarette smokers at six-year screen

\begin{tabular}{|c|c|c|c|c|c|c|c|}
\hline \multirow[b]{2}{*}{ Status at six-year screen } & \multicolumn{3}{|c|}{$\begin{array}{l}\text { Intervention group } \\
3036=\text { No of initial cigarette smokers }=393\end{array}$} & \multicolumn{3}{|c|}{ Control group (10\%) } & \multirow[b]{2}{*}{$p$} \\
\hline & No & $n^{*}$ & $\begin{array}{l}\text { Mean } \\
\text { thiocyanate }\end{array}$ & No & $n^{*}$ & $\begin{array}{l}\text { Mean } \\
\text { thiocyanate }\end{array}$ & \\
\hline $\begin{array}{l}\text { Non-smokers } \\
\text { Cigar or pipe smokers, or both } \\
\text { Cigarette smokers } \\
\text { Average No of cigarettes a day }\end{array}$ & $\begin{array}{r}462 \\
319 \\
2182 \\
17 \cdot 9\end{array}$ & $\begin{array}{r}84 \\
66 \\
444\end{array}$ & $\begin{array}{l}0.32 \\
0.53 \\
0.72\end{array}$ & $\begin{array}{c}62 \\
41 \\
283 \\
20 \cdot 1\end{array}$ & $\begin{array}{r}16 \\
7 \\
56\end{array}$ & $\begin{array}{l}0.27 \\
0.67 \\
0.89\end{array}$ & $\begin{array}{l}\text { NS } \\
\text { NS } \\
<0.01 \\
<0.01\end{array}$ \\
\hline
\end{tabular}

*Random subsample with thiocyanate measure.

observed when the intervention group is compared with the control group for ex-smokers and those who switched to cigar or pipe, or both; however, the lower mean number of daily smoked cigarettes reported by subjects in the intervention group as compared with the control group goes along with a significantly lower mean thiocyanate concentrations in the former as compared with the latter.

\section{Discussion}

In this study the majority (90\%) of the subjects in the control group attended the cardiovascular screening examination for the first time at end-screening. Therefore we assumed that the smoking behaviour as reported by them was unbiased; from these data criteria for specificity and sensitivity concerning thiocyanate concentrations could be established. Thus with a cut-off point of $0.45 \mathrm{mg} / \mathrm{dl}$ only $9 \%$ of those reporting having never smoked were falsepositives. Some of them may have been very moderate and irregular smokers or alternatively were consuming food products resulting in thiocyanate, such as cauliflower, horseradish, or broccoli. Cohen and Bartsch ${ }^{6}$ reported in 426 smokers and 191 nonsmokers a specificity of $81 \%$ and a sensitivity of $93 \%$. With a cut-off point of $100 / \mu \mathrm{mol} / \mathrm{l}(0.58 \mathrm{mg} / \mathrm{dl}) \mathrm{Vogt}$ et al $^{7}$ correctly classified $93 \cdot 3 \%$ of non-smokers and $81 \%$ of smokers. The correlation coefficient between daily smoked cigarettes and thiocyanate concentrations as observed in this study $(0.41)$ lies between a low 0.25 of Cohen and Bartsch ${ }^{6}$ and a somewhat higher 0.46 of Butts et $a l^{8}$ and 0.48 Vogt et al. ${ }^{7}$

It seems that the greatest part of thiocyanate variance is not explained by the number of cigarette smokers but by other variables related to smoking behaviour such as depth of inhalation, frequency of puff, or puff size. ${ }^{9}$

The advantage of thiocyanate over carboxyhaemoglobin as an objective marker of smoking is related to its biological half-life of 14 days, so that recent ex-smokers for some time still have raised thiocyanate concentrations. On the other hand, thiocyanate seems to be resorbed, at least partially, through the oral mucosa, which made us unable to discriminate between cigarettes, cigar, or pipe smokers or between inhalers and non-inhalers. Hence, ex-cigarette smokers who switched to cigar or pipe cannot be divided according to inhalation by thiocyanate concentrations.

The ratio of mean thiocyanate concentration between cigarette smokers and non-smokers was three, comparable to what has been observed in other studies. ${ }^{10} 11$

Several authors have questioned the validity of self-reported behaviour. Thus Sillet $e t a^{1}$ observed that respectively $22 \%$ and $40 \%$ of subjects taking part in clinical trials who reported to have stopped smoking had a high serum carboxyhaemoglobin concentration. In another study, however, 17 out of 19 subjects $(89.5 \%)$ who reported at the follow-up to have stopped smoking had low thiocyanate concentrations. ${ }^{12}$ Under-reporting of number of cigarettes smoked daily in clinical trials has been suggested by several authors on the basis of thiocyanate concentrations. Thus in the study of Kirk et al $^{12}$ subjects who reported a decrease in number of cigarettes smoked had an initial thiocyanate concentration of $142 / \mu \mathrm{mol} / 1$ and $147 / \mu \mathrm{mol} / 1$ at follow-up.

In a sample of the multiple risk factor intervention trial 102 non-smokers and 162 smokers were followed up during one year with base-line and follow-up measurements of thiocyanate concentrations. ${ }^{13}$ The cigarette smokers were given an intervention programme consisting of 10 weekly or bi-weekly meetings of two hours' duration each. Among the subjects who reported a decrease in numbers of cigarettes smoked the authors observed an increase of $75 \%$ in thiocyanate concentration per smoked cigarette. The authors suggest an individual titration to tobacco smoke or alternatively a false under-reporting of smoking behaviour that could be called a "social conforming behaviour." In their final report concerning risk factor modification the multiple risk factor intervention trial reported serum thiocyanate concentrations as measured, both in special intervention and usual care groups at entry and at $12,24,36$, and 48 months. ${ }^{14}$ Compared with 
thiocyanate concentrations for initial non-smokers those for cigarette quitters, both in the special intervention and usual care groups, were much higher. Thus while under-reporting appeared in both groups it was relatively more important in the special intervention group. The authors also question the sensitivity of the thiocyanate method for the detection of smoking reduction in participants who continue to smoke.

We did not perform serial thiocyanate measurements over time which hampers comparison with other studies. Nevertheless, our results fail to confirm the reported pessimistic views concerning the validity of self-reported smoking behaviour in subjects taking part in an epidemiological intervention trial. Indeed, both for ex-cigarette smokers as for subgroups of cigarette smokers no significant differences in thiocyanate concentrations were observed between intervention and control groups. Furthermore, in a subsample of smokers differences in mean number of cigarettes smoked between intervention and control groups were in parallel with significant differences in thiocyanate concentrations. It should be remembered, however, that due to a less aggressive and individualised prevention programme as compared with the multiple risk factor intervention trial study, the results at end-screening in terms of differences between intervention and control groups were weak. The soft intervention procedures perhaps did not induce a feeling of social conforming behaviour in the intervention subjects, hence their more "honest" self-reporting of smoking behaviour.

Study granted by the Belgian "Fonds National de la Recherche Scientifique" (Grant No 20.202).

\section{References}

${ }^{1}$ Sillett RW, Wilson MB, Malcolm RE, Ball KP. Deception among smokers. Br Med J 1978; ii: 1185-6.

${ }^{2}$ Kornitzer M, Dramaix M, Kittel F, De Backer G. The Belgian heart disease prevention project: changes in smoking habits after two years of intervention. Prev Med 1980; 9: 496-503.

${ }^{3}$ Kornitzer M, De Backer G, Dramaix M, Thilly C. The Belgian heart disease prevention project: modification of the coronary risk profile in an industrial population. Circulation 1980; 61: 18-25.

4Aldridge WN. The estimation of microquantities of cyamide and thiocyanate. The Analyst (London) 1945; 70: 474-5.

${ }^{5}$ Michajlovsky N, Langer P. Studien über Beziehungen zwischen Rhodanbildung und kropfbildender Eigenschaft von Nahrungsmittein. I: Gehalt einiger Nahrungsmittel on präformierten Rhodanid. Zeitschrift für Physiologische und Chemie 1958; 312: 26-30.

${ }^{6}$ Cohen JD, Bartsch GE. A comparison between carboxyhemoglobin and serum thiocyanate determinations as indicators of cigarette smoking American Journal of $P H$ 1980; 70: 284-6.

${ }^{7}$ Vogt TM, Selvin S, Widdowson G, Hulley SB. Expired air carbon monoxide and serum thiocyanate as objective measures of cigarette exposure. Am J Public Health 1977; 67: 545-9.

${ }^{8}$ Butts WC, Kuehneman M, Widdowson GM. Automated method for determining serum thiocyanate to distinguish smokers from nonsmokers. Clin Chem 1974; 20: 1344-8.

${ }^{\circ}$ Gritz ER, Baer-Weiss V, Jarvick ME. Titration of nicotine intake with full-length and half-length cigarettes. Clin Pharmacol Ther 1976; 20: 552-6.

${ }^{10}$ Densen PM, Davidow B, Bass HE, Jones EW. A chemical test for smoking exposure. Arch Environ Health 1967; 14: 865-74.

${ }^{11}$ Borgers $\mathrm{D}$, Burckhard $\mathrm{J}$. Thiocyanate as an indicator of tobacco smoking. Prev Med 1979; 8: 351-7.

${ }^{12}$ Kirk CJC, Lund VJ, Woolcock NE, Greenhalgh RM. The effect of advice to stop smoking on arterial disease patients, assessed by serum thiocyanate levels. $J$ Cardiovasc Surg 1980; 21: 568-9.

${ }^{13}$ M R F I T Group. The multiple risk factor intervention trial (MRFIT): a national study of primary prevention of coronary heart disease. JAMA 1976; 235: 825-7.

${ }^{14}$ Neaton JD, Broste S, Cohen L, Fishman EL, Kjelsberg MO, Schoenberger J. (for the MRFIT). The multiple risk factor intervention trial VII. A comparison of risk factor changes between the two study groups. Prev Med 1981; 10: 519-43. 